0

\title{
Water production by reverse osmosis for the manufacture of paint in the automotive industry
}

\author{
F.A. León ${ }^{\mathrm{a}, *}$, A. Ramos-Martín ${ }^{\mathrm{b}}$ \\ "Institute of Intelligent Systems and Numerical Applications in Engineering (SIANI), University of Las Palmas de Gran Canaria, \\ Campus Universitario de Tafira, 35017 Las Palmas de Gran Canaria, Spain, Tel.0034686169516; email: federico.leon@ulpgc.es \\ ${ }^{b}$ Department of Process Engineering, University of Las Palmas de Gran Canaria, Campus Universitario de Tafira, \\ 35017 Las Palmas de Gran Canaria, Spain, Tel.0034928451933; email: alejandro.ramos@ulpgc.es
}

Received 30 August 2020; Accepted 1 November 2020

\section{A B S T R A C T}

Reverse osmosis (RO) is the most extensively used technology in seawater and brackish water desalination. This technology is used in many applications, one of which is the manufacture of automotive paint. In this work, 2 y of operating data of a brackish water reverse osmosis (BWRO) desalination plant were analyzed. The feedwater was taken from groundwater well. The desalination plant had sand and cartridge filters with antiscalant dosing as pre-treatment. The RO system comprised two stages, with 40 pressure vessels (PV) in the first stage and 20 in the second stage, and 6 BWRO elements per PV. Feedwater conductivity ranged between 680 and $2,100 \mu \mathrm{S} / \mathrm{cm}$, and feedwater $\mathrm{pH}$ between 6.05 and 7.55 . Feed pressure increased from 11 to 28 bar due to membrane fouling along the operating period. The RO system had a recovery rate of around $75 \%$, with an approximate production of $7,200 \mathrm{~m}^{3} / \mathrm{d}$. Plant performance over the two study years was evaluated through the calculation of the characteristic parameters of the membrane, including average ionic and water permeability coefficients.

Keywords: Brackish water; Reverse osmosis; Desalination plants; Long-term; Operating data

\footnotetext{
* Corresponding author.
} 